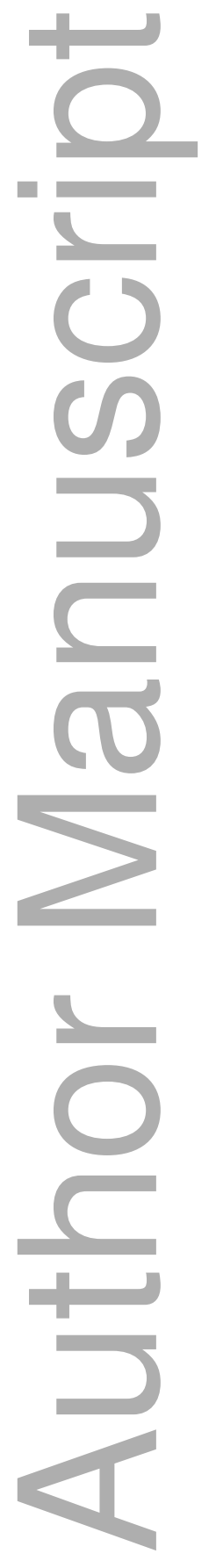

This is the author manuscript accepted for publication and has undergone full peer review but has not been through the copyediting, typesetting, pagination and proofreading process, which may lead to differences between this version and the Version of Record. Please cite this article as doi: $\underline{10.1111 / \text { AEC.12727 }}$

This article is protected by copyright. All rights reserved 


\section{Climate change: Alpine shrubs as ecosystem engineers}

Susanna Venn (Australian National University), Isla Myers-Smith (University of Edinburgh), James Camac (University of Melbourne), Adrienne Nicotra (Australian National University)

- Alpine shrub cover is increasing in response to a warming climate.

- Shrub increases are enhanced by positive feedbacks involving fire responses, snow-drifting patterns, leaf litter decomposition and soil nutrient cycling.

- Critical knowledge gaps surround the rate of shrub range-expansion, the effect of shrubs on local extinctions and the future of mountain catchment water yields.

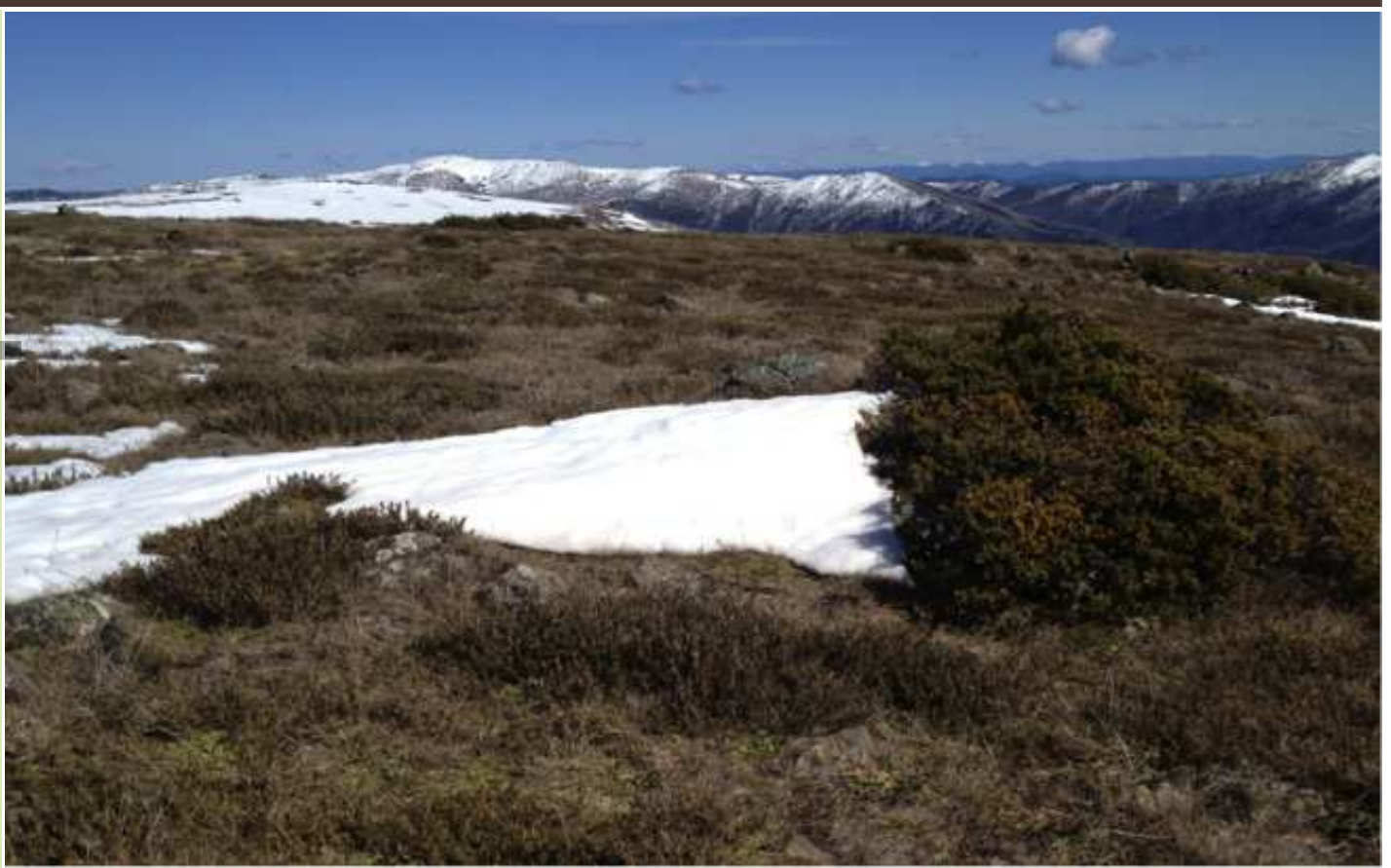

Alpine shrub, Orites lancifolia, effectively creates a snowdrift in its lee, which can promote soil nutrient cycling feedbacks

Climate warming promotes shrub cover and range expansion via landscape

flammability, snow

accumulation and nutrient cycling feedbacks

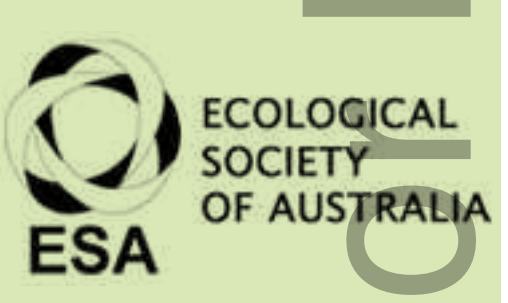

Ecological Society of Australia https://www.ecolsoc.org.au

Further information

Dr Susanna Venn susanna.venn@anu.edu.au (03) 94792327

Chair, Hot Topics Editorial Board DrRachel Standish
Worldwide, shrub cover is increasing across alpine tundra. In Australia, alpine shrub increases match a trend spanning four decades of rising temperatures and declining snowpack. Repeat photography, long-term monitoring, field warming experiments and dendrochronology have revealed that alpine shrubs are responding by encroaching into otherwise non-shrubby communities, such as alpine herbfields and grasslands.

Alpine shrubs readily restrict the growth of other plants via shading and smothering with leaf litter, and they can alter wildlife habitats. Warmer conditions may also exacerbate a feedback between shrubs and fire, whereby increased fire activity due to highly flammable foliage and leaf litter, stimulate vigorous re-sprouting and seeding, resulting in further increases in shrub cover.

Some shrub growth forms interact with winter processes; they can accumulate snow in their lee, thereby insulating soils from extreme winter temperatures. These effects may also promote a second feedback whereby deeper snowpack, warmer soils and higher soil moisture, coupled with leaf litter under shrub canopies, increases microbial activity. These effects in turn, can enhance soil nutrient cycling and ultimately promote shrub growth. Deeper snowpack around shrubs also contributes to winter and spring water yields in mountain catchments.

Given that alpine shrub range-expansion has the potential to significantly modify existing landscape flammability, winter processes and ecosystem function, alpine shrubs effectively act as ecosystem engineers. There is an urgent need for land managers to monitor changes in shrub abundance, and for stakeholders to understand these processes in order to determine whether increases in shrub cover and shrub encroachment will result in alternate stable states in alpine vegetation, local plant and/or animal extinctions, and whether an overall declining snowpack will mitigate or exacerbate these processes. 


\section{Supporting Evidence}

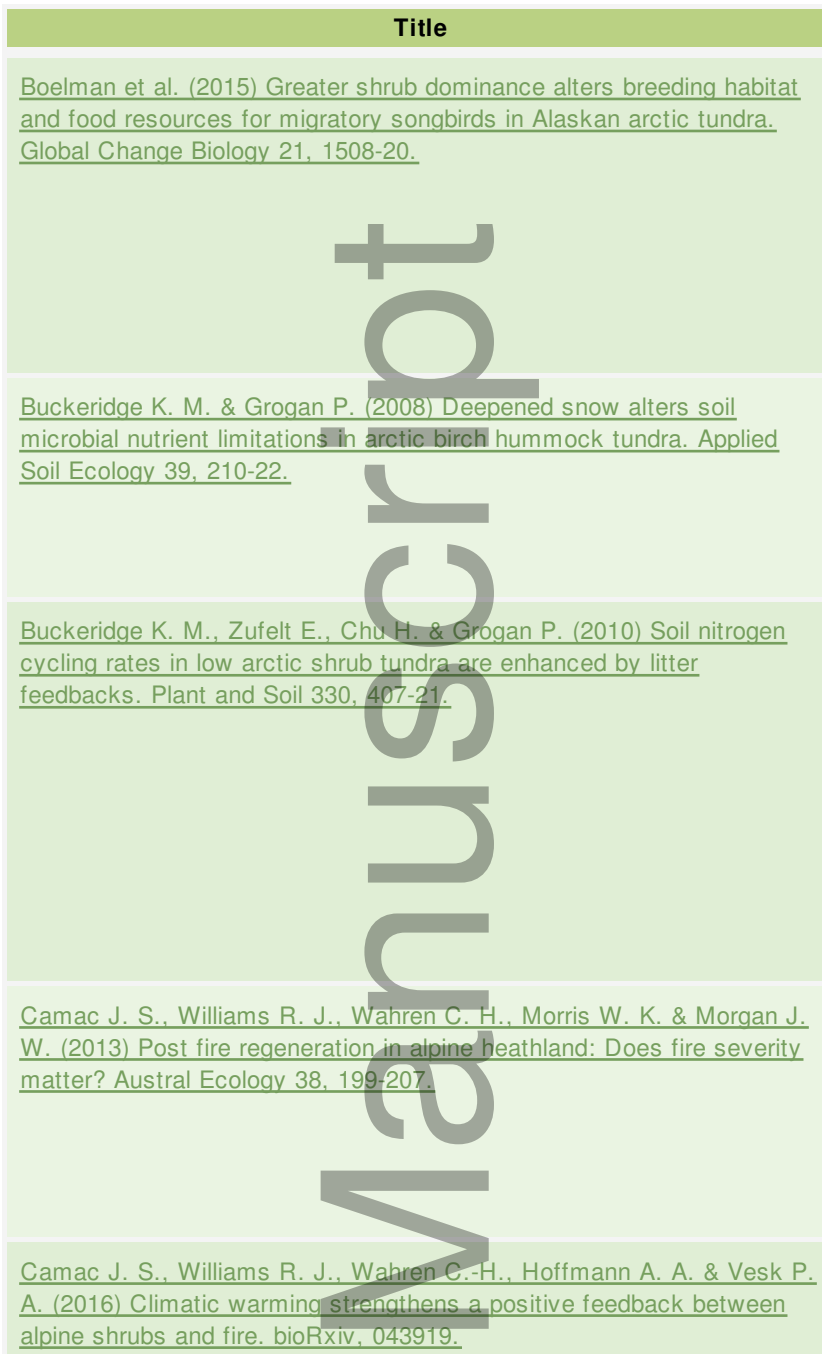

Camac J. S., Williams R. J., Wahren C.-H., Jarrad F., Hoffmann A. A. $\&$ Vesk P. A. (2015) Modeling rates of life form cover change in burned and unburned alpine heathland subject to experimental warming. Oecologia 178, 615-28.

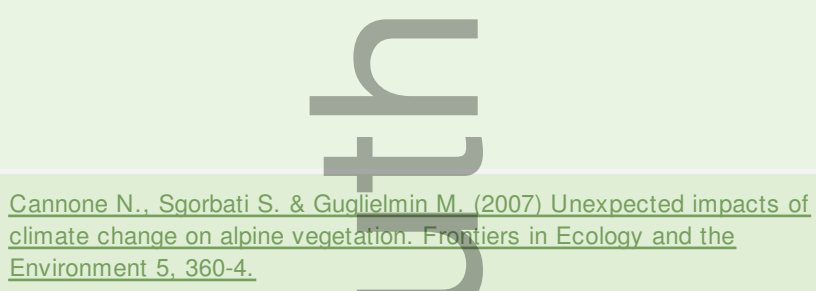

Aim

To quantify the vegetation and arthropod community characteristics in both graminoid and shrub dominated tundra, in order to understand how increasing deciduous shrub dominance may alter breeding songbird habitat.

\section{To determine nutrient} limitations to soil microbial growth and activity in late winter under ambient and experimentally deepened snow.

To determine the role of $\mathrm{N}$ in controlling shrub growth, by comparing $\mathrm{N}$-cycling in tall birch (Betula glandulosa) and surrounding dwarf birch hummock vegetation on similar soils.

To examine the effects of variation in fire severity on plant diversity and vegetation composition, 5 years after the widespread fires of 2003.

To examine warming and fire effects on recruitment, growth and survival of seedlings of everygreen obligate seeding alpine shrubs.

To examine how the interactions between experimental warming, the abundance of bare ground (a measure of past disturbance) and neighboring life forms (a measure of life form interaction) affect rates of cover change in alpine shrubs, graminoids and forbs.

To investigate the level of ecological hierarchy at which climate change can be seen by analyzing changes in vegetation distribution, community dynamics, and vegetation series (ie shrublands, grasslands, wetlands) in the Italian Alps for the period 1950-2003.

Chu H. \& Grogan P. (2010) Soil microbial biomass, nutrient availability and nitrogen mineralization potential among vegetation-types in a low arctic tundra landscape. Plant and Soil 329, 411-20.
To investigate the soil microbial biomass, nutrient availability, nitrogen $(\mathrm{N})$ mineralization potential and nitrification potential in four of the principal vegetation types across the low Arctic: dry heath, birch hummock, tall birch and wet sedge.

\section{Key Results}

Lapland longspur nests were found in sedge-dominated tussock tundra where shrub height does not exceed $20 \mathrm{~cm}$, whereas White-crowned sparrows nested only under shrubs between $20 \mathrm{~cm}$ and $1 \mathrm{~m}$ in height, with no preference for shrub species. Shrub canopies had higher canopy-dwelling arthropod availability (i.e. small flies and spiders) but lower ground-dwelling arthropod availability (i.e. large spiders and beetles).

Deeper snow may increase microbial nutrient pools and can alter the physiological functioning of the soil microbial community in late winter, suggested that microbial $\mathrm{N}$ release and its availability to plants during spring thaw may be enhanced.

Stable isotope tracer analysis revealed $\mathrm{N}$ pools and cycling rates were $\sim 3$ times larger and faster in the tall birch ecosystem in the late growing season, just prior to leaf senescence. Gross NH4+-N production rates in these ecosystems correlated positively with larger pools and production rates of dissolved soil $\mathrm{C}$ and $\mathrm{N}$, higher quality litter inputs and lower soil $\mathrm{C}$. Analyses of the soil microbial community in both ecosystems indicated similar fungal dominance (epifluorescence microscopy) and similar compositions of the principal fungal or bacterial phylotypes (denaturing gradient gel electrophoresis).

In both closed and open heathlands, there were few differences in floristic diversity, cover of dominant species and community composition, across the strong fire severity gradient. Support for the null model, with only limited support for either the linear and intermediate disturbance models. Vegetation attributes in burnt vegetation were converging towards that of the unburnt state.

Fire substantially increased shrub seedling establishment (up to 32-fold) and that warming doubled tall shrub seedling growth rates and could increase grass, or competitive effects of grass on shrub seedling growth and survival.

Experimental warming altered rates of life form cover change by reducing the negative effects of neighboring life forms and positive effects of bare ground.

Shrubs showed rapid expansion rates of $5.6 \%$ per decade at altitudes between $2400 \mathrm{~m}$ and $2500 \mathrm{~m}$.

Soil $\mathrm{N}$ mineralization data suggest that climate warming may enhance $\mathrm{N}$ availability in tall birch (shrub) soils more than in birch hummock soils, and therefore that increases in shrub densities across the landscape are most likely within and directly around current tall shrub patches. 
Essery R. \& Pomeroy J. (2004) Vegetation and topographic control of wind-blown snow distributions in distributed and aggregated simulations for an Arctic tundra basin. Journal of Hydrometeorology 5, 735-44.

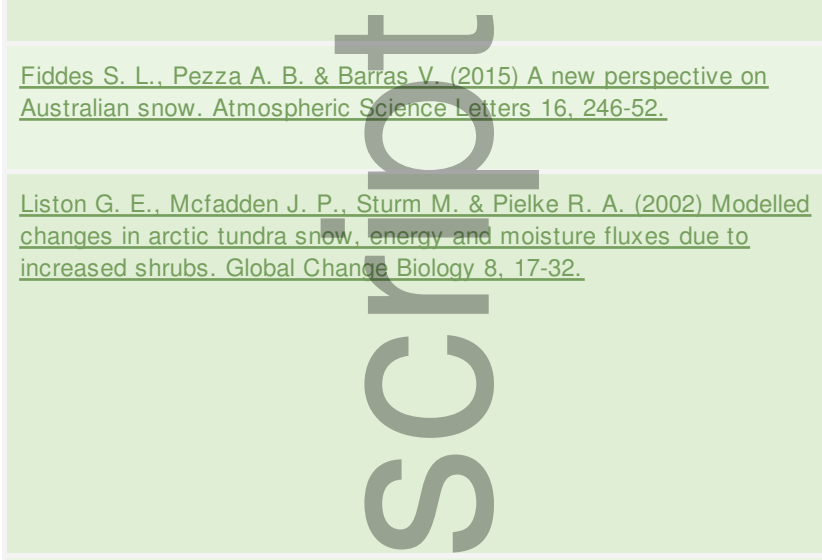

Maestre F. T., Eldridge D. J. \& Soliveres S. (2016) A multifaceted view on the impacts of shrub encroachment. Applied Vegetation Science 19, $\underline{369-70 .}$

McDougall K. L. (2003) Aerial photographic interpretation of vegetation changes on the Bogong High Plains, Victoria, between 1936 and 1980. Australian Journal of Botany 51, 251-256.

Myers-Smith et al. (2011) Shrub expansion in tundra ecosystems: dynamics, impacts and research priorities. Environmental Research Letters 6, 045509
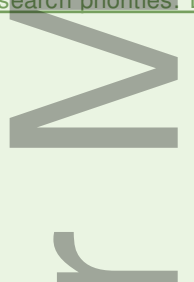

Myers-Smith I. H., Elmendorf S. C., Beck P. S., Wilmking M., Hallinger M., Blok D., Tape K. D., Rayback S. A., Macias-Fauria M. \& Forbes B. C. (2015) Climate sensitivity of shrub growth across the tundra biome. Nature Climate Change 5, 887-91

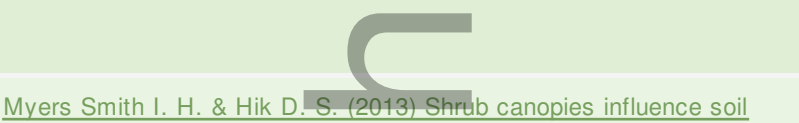

Myers Smith I. H. \& Hik D. S. (2013) Shrub canopies influence soil temperatures but not nutrient dynamics: an experimental test of tundra snow-shrub interactions. Ecology and evolution 3, 3683-700.

Scherrer P. \& Pickering C. M. (2005) Recover of alpine vegetation from grazing and drought: data from long-term photoquadrats in Kosciuszko National Park, Australia. Arctic, Antarctic and Alpine Research 37, 574$\underline{84 .}$

Sturm M., Holmgren J., McFadden J. P., Liston G. E., Chapin III F. S. \& Racine C. H. (2001a) Snow-shrub interactions in Arctic tundra: a hypothesis with climatic implications. Journal of Climate 14, 336-344.
To produce a finescale model of blowing snow is to simulate the characteristics of snow cover in a low-Arctic catchment with moderate topography and partial shrub cover. To investigate the influence of changing shrub characteristics by performing a sequence of simulations with varying shrub heights and coverage.

To compile a new and robust snow accumulation data set for Australian alpine areas.

To examine how shrub expansion would affect the arctic

snow+atmosphere+biosphere system using a threedimensional snow-transport model and an energy-balance snowmelt model to simulate the effects of increased height and distribution of arctic shrubs.

To call for a more holistic view when assessing shrub encroachment and land-cover change.

To compare thesubalpine vegetation of between 1936 and 1980 using aerial photographs and a point sampling technique.

To synthesize findings that has documented shrub expansion in arctic, highlatitude and alpine tundra, present a conceptual framework and explore causes, feedbacks and implications of increased shrub cover in tundra ecosystems.

To analyse annual shrub growth data from 37 Arctic and alpine sites in 9 countries to explore climate-growth relationships.

To determine the influences of canopies on soil temperatures and nutrient cycling parameters.

To re-examine permanent phtotoquadrats for evidence of vegetation change.

To point out the existence and potential importance of winter biogeophysical linkages, and suggest that they play role in the general response of the tundra to climate change.
Increasing shrub height gives an increase in snow depth within the shrub-covered areas, up to a limit determined by the supply of falling and blowing snow, but increasing shrub coverage gives a decrease in snow depths within shrubs as the supply of blowing snow imported from open areas is reduced.

Both maximum snow depth and total snow accumulation have declined over the last 25 years.

The simulated shrub enhancement increased the averaged snow depth of the domain by $14 \%$, decreased blowing-snow sublimation fluxes by $68 \%$, and increased the snowcover's thermal resistance by $15 \%$. The shrub increase also caused significant changes in snow-depth distribution patterns; the shrub-enhanced areas had deeper snow, and the nonmodified areas had less snow.

Shrub encroachment may not always have negative impacts on an ecosystem, and encroachment will have multiple outcomes for the biota, functions and services of terrestrial ecosystems.

Most change over time was from grassland to open heathland and from open heathland to closed heathland.

Warming temperatures, changes in snow cover, altered disturbance regimes as a result of permafrost thaw, tundra fires, and anthropogenic activities or changes in herbivory intensity are all contributing to observed changes in shrub abundance.

the sensitivity of shrub growth to climate was: (1) heterogeneous, with European sites showing greater summer temperature sensitivity than North American sites, and (2) higher at sites with greater soil moisture and for taller shrubs (for example, alders and willows) growing at their northern or upper elevational range edges.

Shrub canopy cover was a dominant factor influencing the soil thermal regime. No strong evidence of increased soil decomposition, $\mathrm{CO} 2$ fluxes or nitrate or ammonia adsorption under artificial shrub canopy treatments when compared with unmanipulated open tundra.

Bare areas were initially colonized by herbs, with native grasses, the lateral expansion of existing shrubs, and other herb species eventually replacing the colonizing herbs.

Where shrubs are more abundant and larger, greater amounts of drifting snow are trapped and suffer less loss due to sublimation. The snow in shrub patches is both thicker and a better thermal insulator per unit thickness than the snow outside of shrub patches. As a consequence, winter soil surface temperatures are substantially higher, a condition that can promote greater winter decomposition and nutrient release, thereby providing a positive feedback that could enhance shrub growth. 


\section{Sturm M., Racine C. \& Tape K. (2001b) Climate change: increasing shrub abundance in the Arctic. Nature 411, 546-7.}

Sturm M., Schimel J., Michaelson G., Welker J. M., Oberbauer S. F., Liston G. E., Fahnestock J. \& Romanovsky V. E. (2005) Winter biological processes could help convert arctic tundra to shrubland. Bioscience 55, 17-26.

\section{To present evidence of a} widespread increase in shrub abundance in Arctic landscapes over 50 years.

To draw together evidence which demonstrates how winter processes could help convert the Arctic tundra to shrubland.

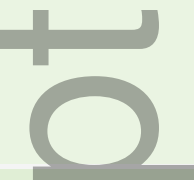

Vankoughnett M. R. \& Grogan P. (2016) Plant production and nitrogen accumulation above-and belowground in low and tall birch tundra communities: the influence of snow and litter. Plant and Soil, 1-16.

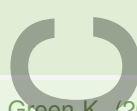

Venn S. E., Pickering C. M. \& Green K (2012) Short-term variation in species richness across an altitudinalgradient of alpine summits. Biodiversity and Conservation 21, 3157-3186.

\section{(20.014)}

Venn S., Pickering C. \& Green K. (2014) Spatial and temporal functional changes in alpine summit vegetation are driven by increases in shrubs and graminoids. AoB plants 6, plu008.
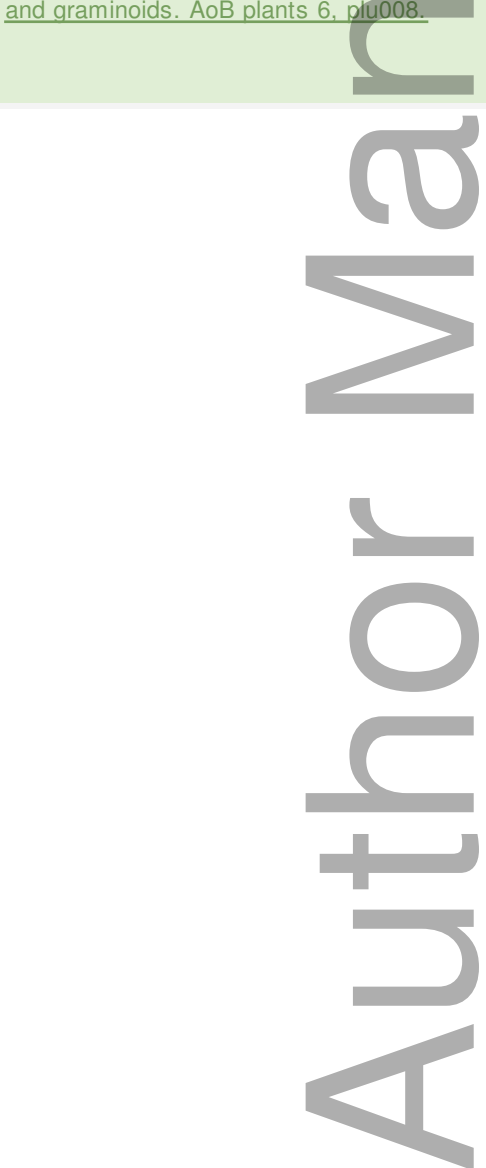

To investigate if deeper snow is a mechanism for enhanced shrub growth.

To examine changes in species richness with respect to climate and altitude over a 7 year period.

To investigate temporal and spatial changes in alpine summit plant community composition using plant functional traits.
Dramatic increases in the height and diameter of individual shrubs, in-filling of many areas and expansion of shrubs into previously shrub-free areas.

Evidence suggests that winter biological processes are contributing to this conversion through a positive feedback that involves the snow-holding capacity of shrubs, the insulating properties of snow, a soil layer that has a high water content because it overlies nearly impermeable permafrost, and hardy microbes that can maintain metabolic activity at temperatures of $-6 \mathrm{C}$ or lower. Increasing shrub abundance leads to deeper snow, which promotes higher winter soil temperatures, greater microbial activity, and more plant-available nitrogen. High levels of soil nitrogen favor shrub growth the following summer.

Deciduous birch shrub new shoot production was $23 \times$ large and total vascular shoot to belowground biomass ratios were higher in the tall birch tundra than the birch hummock $(\sim 0.7$ and $\sim 0.4$, respectively), indicating that the combination of deeper snow together with other internal feedbacks greatly enhanced birch growth.

Mean species richness increased at the whole-of-summit scale from 45 to 50 species (about $12 \%$ ). At this scale, the rate of species richness increase was almost one new species per year, with 15 new species recorded at one summit. Here, shrub and graminoid species showed the largest increases.

Increases in high SLA plants at high elevations and low SLA plants at lower elevations, driven by an increasing domiance of tall shrubs and graminoids at the lower-elevation summits over 7 years. 


\section{University Library}

\section{- M M I N E R VA A gateway to Melbourne's research publications}

Minerva Access is the Institutional Repository of The University of Melbourne

Author/s:

Venn, S;Myers-Smith, I;Camac, J;Nicotra, A

Title:

Climate change: Alpine shrubs as ecosystem engineers

Date:

2019-08-01

Citation:

Venn, S., Myers-Smith, I., Camac, J. \& Nicotra, A. (2019). Climate change: Alpine shrubs as ecosystem engineers. AUSTRAL ECOLOGY, 44 (5), pp.927-930. https://doi.org/10.1111/ aec.12727.

Persistent Link:

http://hdl.handle.net/11343/285766 